\title{
Why Corporate Political Connections Can Impede Investment
}

\author{
Robert Kubinec $^{* 1}$, Haillie Lee ${ }^{2}$, and Andrey Tomashevskiy ${ }^{3}$ \\ ${ }^{1}$ Division of Social Sciences, New York University Abu Dhabi \\ ${ }^{2}$ Department of Political Science, Rutgers University \\ ${ }^{3}$ Department of Political Science and International Relations, Seoul \\ National University
}

April 22, 2021

\begin{abstract}
We present an experiment that manipulates corporate political connections to understand whether a company's political influence is a barrier or an inducement to intercorporate investment. Our data come from a survey of 3,329 firm employees and managers located in Venezuela, Ukraine and Egypt. On the whole we find that our respondents do not prefer to invest in companies with political connections. These results are highly conditional on the respondent's company: respondents from highly connected companies prefer to invest in companies with political connections, while respondents at less-connected companies prefer to invest in companies without political connections. We believe that what explains this finding are differences in how companies with and without connections manage liability as our survey data shows connected companies are much more likely to employ informal rather than formal mechanisms to resolve disputes. As a result, we believe that unconnected companies are more likely to invest in other unconnected companies to ensure that their property rights are protected. ${ }^{1}$
\end{abstract}

\footnotetext{
*Corresponding author: rmk7@nyu.edu

${ }^{1}$ Code and data to reproduce analyses is available via the Github repository: https://github.com/ saudiwin/exprop_survey_public. We thank participants of the 2020 International Political Economy Society Conference, participants of the 2020 American Political Science Association Annual Conference and Jong Hee Park and Sung in Kim for helpful comments. We thank the Niehaus Center for Globalization and Governance at Princeton University for providing funding for this project. We also thank the Division of Social Sciences at New York University Abu Dhabi and Rutgers University for funding and support.
} 


\section{Introduction}

Firms operating in high-corruption countries with weak property right often rely on informal connections to political agents to succeed in an environment fraught with risks (Fisman 2001; Faccio, Masulis and McConnell 2006; Markus 2012, 2015). These types of nonmarket strategies can be effective in securing preferential access to loans and contracts, as well as providing protection from predation by government agents. A large body of work shows that political connections are an important aspect of business-government relations and firms' non-market strategies in countries with weak institutions (Shleifer and Vishny 1993; Samphantharak and Malesky 2008), but at the same time, corruption writ large is a hindrance to investment and innovation (Mauro 1997). In this paper, we examine to what extent political connections are an asset or a hindrance to inter-firm cooperation and investment as intercorporate investment represents a sizable share of investment activity across countries (Fedenia, Hodder and Triantis 1994).

Firms undertake strategic investments in other companies to improve market position and increase profits. In high-corruption environments, cooperation and inter-firm investment between domestic and foreign firms is often necessary to avoid expropriation or secure access to international arbitration (Henisz 2000; Betz and Pond 2019). For these reasons, politically connected firms should be more attractive partners for cooperation and investment since partner firms may share some of the benefits of political connections (Bhandari 2020). However, it is possible that connected firms could be unattractive investment partners since such firms may be more likely to break contracts and engage in opportunistic behavior (Williamson 1979). Connected firms may also have the "wrong" type of connections to political agents out of favor with the ruling regime in a given country (Albertus and Menaldo 2012; Frye and Yakovlev 2016). Cooperation is less attractive if firms with the "wrong" connections, along with their partner firms, face more expropriation and government predation. Although existing research suggests that political connections are a valuable asset, it is not clear if and how much outside investors would value political relationships when considering 
whether to invest in a connected company.

A central problem in evaluating this research question is that political connections are almost never randomly assigned to companies and thus analyses with cross-sectional or even panel data can be obscured by selection bias. To address these inferential concerns, we conducted an online survey experiment by using Facebook advertisements to recruit 3,329 business employee and manager respondents in Egypt, Ukraine and Venezuela. Survey respondents were asked to describe their firm's characteristics, degree of political connections, and experience with government predation and expropriation.

We implemented an investment choice experiment in the survey that allows us to experimentally manipulate company political connections along with other company-level variables such as profitability, size and country of origin. Respondents were presented with characteristics of two hypothetical firms and asked to choose how much money to invest in each. On the whole, respondents were less likely to choose companies with political connections. Examination of treatment heterogeneity showed that this effect is driven by the experiences of respondents at their companies. Respondents at companies with more political connections (and specifically more valuable political connections) prefer to invest in connected companies, while respondents at non-connected companies (i.e., the majority of the sample) prefer to invest in non-connected businesses. We also show that a companies' ability to use informal forms of redress is also a moderator of the treatment, suggesting that the reason political connected respondents prefer politically-connected investments is due to the need to have equal standing when addressing contractual disputes.

This paper makes contributions to research on political connections, inter-firm cooperation, and business-government relations by experimentally evaluating the role of political connections with respect to investment. The highly conditional effects of connections may help explain why in high-corruption countries private domestic investment tends to be lower on average, depressing long-run economic growth (Tanzi and Davoodi 1998). Our theory and results suggest that firms operating in high-corruption environments must consider not only 
the risk of expropriation and opportunism by government agents but also risks associated with their business partners (Henisz 2000; Qian, Pan and Yeung 2010; Markus 2012). This contributes to a large literature on property rights, expropriation, and political risk in political science, economics and management that has largely focused on acts of expropriation by government agents (Kobrin 1987; Jensen 2003, 2008; Li and Resnick 2003; Li 2009). In adopting a cross-national approach, we are also able to show that the role of political connections and inter-firm cooperation is relatively similar across countries with differing political systems yet similar issues with corruption.

\section{Theory}

A large literature on business-government relations points to the importance of political connections as a component of firms' political, non-market strategies. Past studies in politics and economics have argued that companies' experiences in high-corruption states are strongly affected by informal ties; firms with strong political connections receive significant preferential treatment (e.g. better access to credit market and contracts) from governments. Political connections involve direct ties between a firm and government structures (Samphantharak and Malesky 2008; Schoenherr 2018). Politically connections are likely to increase firms' investment activity and are likely to increase firms' value (Roberts 1990; Fisman 2001). For example, Faccio, Masulis and McConnell (2006) find that politically connected firms are more likely to be bailed out relative to comparable non-connected firms. Similarly, Claessens, Feijen and Laeven (2008) show that firms with political connections enjoy better access to bank financing.

In this paper we adopt a more expansive conceptualization of political connections that includes both formal and informal ties to government institutions and politicians. These ties may involve a CEO's, board member's, or manager's past or current appointments to positions in governmental institutions. These ties may also involve personal relationships and 
can involve company owners, managers, and board members. Alternatively, political connections may include membership in political parties, past or present positions in government, or direct family ties to presidents or prime ministers.

When predation is common, officials may create exclusive "spheres of influence" that corresponds to formal and informal hierarchical relationships. The presence of these ties implies that officials hold some stake in the survival of the firm and are willing to use influence to intervene on behalf of the firm. Given this, officials may be more reluctant to target firms that have ties to other, potentially more influential, government officials (Fried, Lagunes and Venkataramani 2010). Political ties can work as insurance and protection from uncontrolled and unpredictable predation if some subset of officials, who would otherwise target a firm, are deterred from interfering with its operations (Keillor, Wilkinson and Owens 2005; Campos, Lien and Pradhan 1999). Firms with political connections may thus incur fewer political risks and will be able to operate more efficiently compared to politically unconnected firms (Galang 2012). ${ }^{2}$

How do political connections affect inter-firm cooperation and investment? Existing research does not give a direct answer, though we can infer one based on previous findings. In general, it would seem that political connections should provide important benefits for investors and business partners. Firms cooperate by entering into strategic alliances such as joint ventures or equity alliances in order to leverage resource complementarities and improve market share. Political factors may also drive incentives to cooperate if strategic alliances reduce risks of expropriation and predation by government agents. Firms may thus enter into joint ventures with foreign or domestic firms to increase protection of property rights (Henisz 2000; Betz and Pond 2019). Structural institutional factors, as well as firm-level characteristics, may reduce transaction costs and increase the likelihood and efficiency of inter-firm cooperation (Farrell 2005; Nielsen 2007).

\footnotetext{
${ }^{2}$ This does not necessarily imply that politically connected firms incur no costs. In building ongoing relationships with government officials, politically connected firms may simply be transforming the unpredictable costs of corruption (e.g. unanticipated and intermittent incidents of expropriation) into a stabler stream of ongoing costs to nurture the political connections (e.g.bribes) (Wei 1997).
} 
However, while the beneficial aspects of connections on investment appear to be the most likely outcome, there is some research suggesting downsides as well. Cooperation with politically connected firms may carry additional risks; transaction costs, risk of hold-up and opportunism, and incomplete contracts can generate new uncertainties and costs for cooperating firms. Politically connected firms may engage in more opportunistic behavior if political connections shield connected firms from costly punishment (Bhandari 2020). In a high-corruption environment, connected firms are more likely to rely on various informal means of dispute resolution instead of formal institutions, such as courts or law enforcement authorities. Since formal institutions are less likely to be effective and efficient, connected firms are more likely to leverage their connections to government agents and bypass formal institutions altogether.

The main reason we believe that connections could be a problem for intercorporate investment is because strategic alliances involving connected and unconnected firms imply a power imbalance. Since unconnected firms lack informal ties to government agents, unconnected firms must rely on formal dispute resolution mechanisms in the event of conflict with connected firms (Gans-Morse 2017; Marques, Levina, Kazun and Yakovlev 2020; Markus 2012). If connected firms use their ties to government officials to bypass formal institutions such as courts and escape formal penalties, connected firms are more likely to act opportunistically when interacting with unconnected firms. In the event of a dispute, connected firms are more likely to leverage the power imbalance receive a favorable outcome due to their connections to government agents.

Unconnected firms must then weigh the risks of opportunistic behavior when evaluating prospective partners. This type of risk is likely to be lower for pairs of unconnected firms since both firms lack political connections and would need to rely on formal institutions with a more level playing field. This logic implies that unconnected firms are less likely to cooperate with connected firms and are more likely to interact with other unconnected firms. Since connected firms will be less likely to locate unconnected partners, connected firms will 
then cooperate with other connected firms. If both firms have political connections, both have access to informal as well as formal means of dispute resolution.

Furthermore, firms may have access to the "wrong" connections to governments agents out of power. Officials that are in office currently are more likely to exert influence on behalf of a particular firms, compared to former officials. If there has been a recent regime transition, association with former officials may actually be hazardous. Albertus and Menaldo (2012) note that a new dictator may expropriate firms associated with preexisting elites to signal his loyalty to the organization that has launched him into power. Frye and Yakovlev (2016) find that connections to the ruling party matters. Firms with close economic ties to the state felt more vulnerable to government expropriation after a surprising parliamentary election that weakened the bargaining power of the ruling party. When choosing partners for cooperation, firms with the "wrong" connections may thus also choose to cooperate with unconnected firms, rather than firms that benefit from their current connections. The imbalance in power between firms is thus likely to persist among connected firms if some firms have ineffective connections to officials that are out of power.

As an illustration, we present some descriptive patterns from the firm survey we describe in this paper. We ask respondents to describe their firm's level of political connections on a 10-point scale, ranging from unconnected at 0 , to strong political connections at 10 . We also ask respondents to describe the efficacy of their connections on a 10 point scale. This variable ranges from "hurt by connections" at 0, to "benefits from connections" at 10. Figure 1 plots the relationship between these variables. While the two variables are highly correlated (correlation coefficient of .6), suggesting that firms tend to benefit from political connections, we observe a considerable amount of off-diagonal cases as well. Some highly connected firms thus report that they are hurt by their connections, suggesting that effects of political connections are not uniform.

In our empirical analysis, we examine how firms' investment choices are affected by political connections. Investment represents a type of cooperative behavior that is useful for 
Figure 1: Political Connections and Efficacy

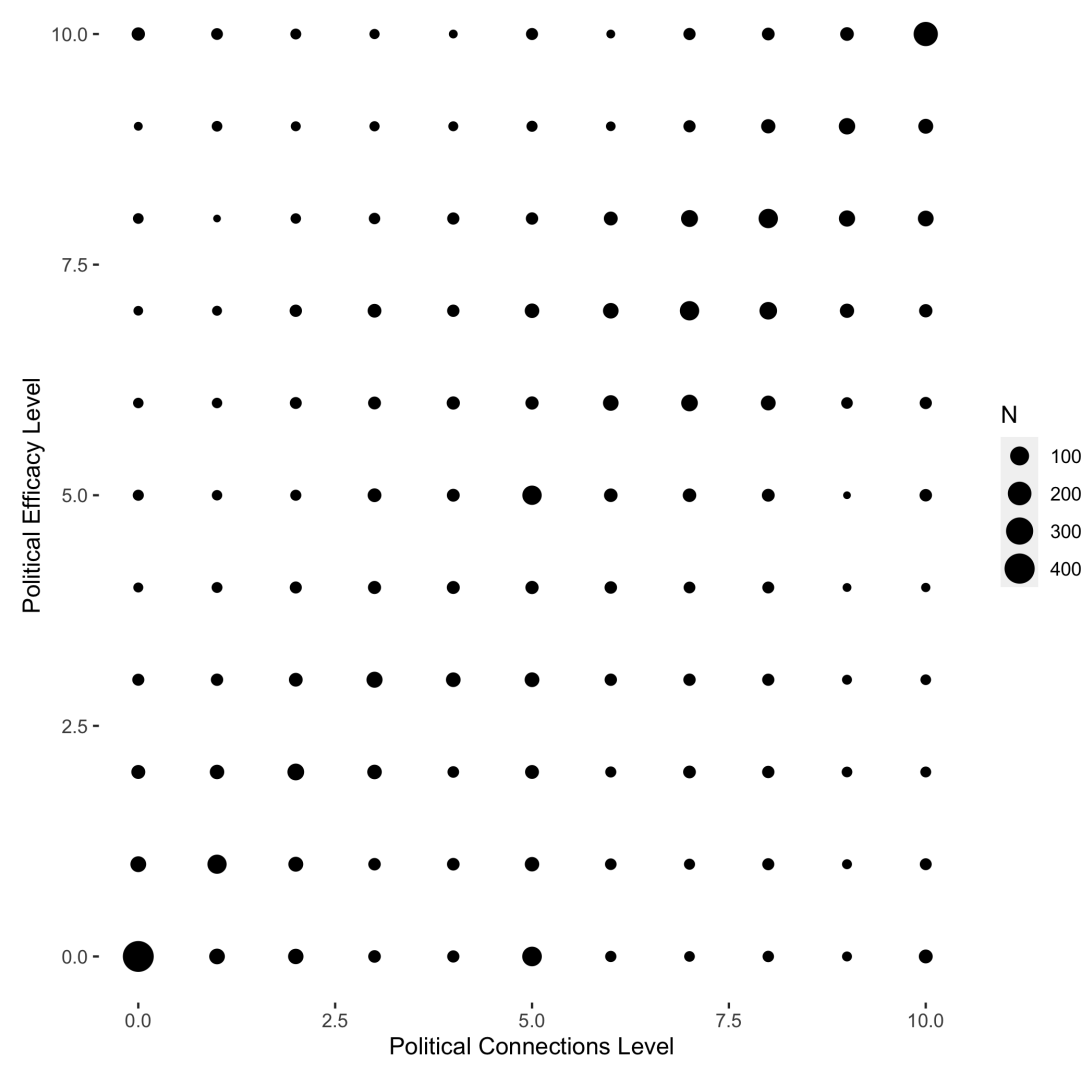

evaluating the above theories. To the extent that firm-government relations affect a firm's profits and earning potential, as well as the security of property rights, these are factors that should play a direct role when firms make inter-firm investment decisions. Since existing theory and evidence does not give a clear answer concerning the relationship between connections and investment, we attempt to add some clarity through our empirical analysis. Our experiment allows us to examine political connections in much greater detail than has previously been possible. To examine the relationship between investment and political connections, we test the following competing hypotheses:

H1a: Politically-connected companies should receive more investment than nonconnected companies.

H1b: Politically-connected companies should receive less investment than nonconnected companies. 
These hypothesis are based on the differing logics described above. Falsifying one of these hypotheses would help to resolve the ambiguous predictions based on existing research. ${ }^{3}$

\section{Inferential Methods}

There are serious inference problems that we must overcome to identify the effect of corporate political connections on firm investment. Figure 2 shows a graphical depiction of how we think that a company's political connections, denoted $P C$, are likely to influence investment into the company, denoted $I$. We include as well TFP for total factor productivity, which we think should also increase the probability of investment. We believe that a company's political connections are likely to influence the probability of investment indirectly by affecting productivity (path $c$ ) and directly via investors' perceptions of the value of connections (path $a$ ). What we are primarily interested here is identifying path $a$, though the effect of $T F P$ via path $b$ is also of interest. However, we cannot identify either of these paths in a regression model with cross-sectional data because of $S$, which stands for sample selection bias.

This variable, which is unobservable given a cross-section of companies, influences both the level of TFP and the level of political connections $P C$. It does so because of an ongoing process by which firms that are more productive, and hence more profitable, obtain political connections over time. In addition, firms with negative political connections, such as connections to an administration that falls out of power, are removed from the sample either because their firm goes bankrupt or because they become the subject of a corruption investigation. By comparison, companies that are very productive but do not have political connections may select out of the sample because they become targets by government bureaucrats or better-connected rivals. As a result, if we regress a measure of political connections and a measure of $T F P$, such as profitability, on observed investment decisions, we do not know how much the resulting associations are due to the influence of political connections, firm-level

\footnotetext{
${ }^{3}$ These hypotheses are re-worded versions of the hypotheses in our pre-registration for the sake of clarity.
} 


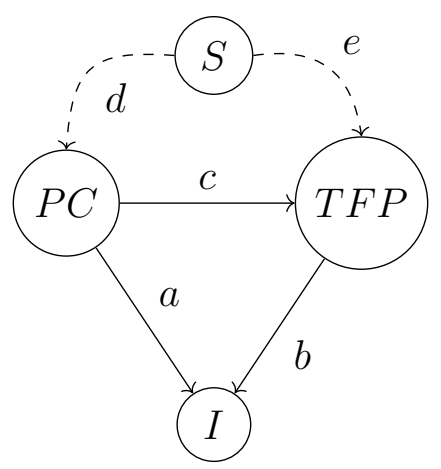

Figure 2: Directed Acyclic Graph (DAG) showing Influence of Sample Selection Bias $(S)$ The figure shows the influence of an unobserved confounder $S$, which stands for the over-time selection process by which politically-connected firms are more likely to remain in the sample and also to be more profitable. As a result, the effects of political connections $P C$ and total factor productivity $T F P$ on investment cannot be identified without adjusting for $S$ or manipulating $P C$.

productivity or ongoing selection processes that influenced both of these.

There are two ways we could try to address this difficult inference problem. The first would be to collect data on $S$, i.e. to understand the selection process. We could have a chance of doing so if we had enough longitudinal data and a thorough understanding of how the selection process works via paths $d$ and $e$. Unfortunately, such data is not widely available outside of developed industrial countries (and even there it can be hard to obtain). As a result, much of the literature is restricted to making comparisons without being able to parse out the selection bias latent in the estimates, even after the hard work of collecting data on political connections has been accomplished.

However, there is a second way to address this inference process, and that is to intervene on $P C$ in such a way that we can assign a value to $P C$ independent of $T F P$ or $S$. If we can do so, we can block the backdoor path on paths $d$ and $e$ that obfuscates the effect of connections and TFP with selection bias. As a result, we can achieve causal identification of this parameter even though we only have data observed at a single point of time. In essence, by randomizing $P C$ independently of $S$ or $T F P$, we can approximate counterfactuals which are missing from the observed distribution of firms. For example, we could see how well very productive but poorly connected companies fare against poorly productive but highly connected companies, or how two companies fare in terms of investment if each had 
a similar level of productivity but one had a higher level of connections. To implement this identification strategy, we designed a conjoint experiment of plausible investment scenarios which we explicate in the next section, and see how business managers and employees respond to manipulations of these variables.

\subsection{Data}

To collect data for our conjoint experiment, we conducted an online survey using Facebook advertisements in three countries: Ukraine, Egypt and Venezuela. Our survey contains the experiment as well as questions that allow us to collect observational firm-level characteristics. Ukraine, Egypt and Venezuela are appropriate countries for this type of analysis since these are high corruption countries where firms face political risks including demands for bribes, harassment, and shake-downs by government agents and a higher risk of expropriation. All of these countries are near the bottom of the 2019 Transparency International Corruption Perception Index: Ukraine ranks 126/198, Egypt is 106/198 while Venezuela is 173/198. However, Venezuela, Egypt and Ukraine have very different institutions: Venezuela and Egypt are authoritarian regimes while Ukraine is a democracy where elections are generally recognized to be free and fair (though high levels of conflict undermine government sovereignty in the eastern part of the country). Our country selection for this reason follows a most-different systems design in which we identify countries that are similar in terms of our independent variable of interest-corruption and crony business-state relations-while maximizing diversity in terms of ancillary factors that could affect investment such as the type of political institutions. By so doing we hope to be able to see if political connections tend to have similar effects across diverse institutions, increasing the external validity of the analysis.

Our survey targeted individuals 18-64 who own or are currently employed across all firms in Ukraine, Egypt and Venezuela. We collected responses from 3,329 individuals, including employees, managers and CEOs of companies in the target countries. These individuals rep- 
resent firms varying across sectors, income, number of employees, and includes both domestic as well as wholly owned subsidiaries and joint ventures of foreign firms. Our sample is split fairly evenly, with $59.08 \%$ employee respondents and $40.92 \%$ management respondents.

\section{Figure 3: Sample Sector Distribution}

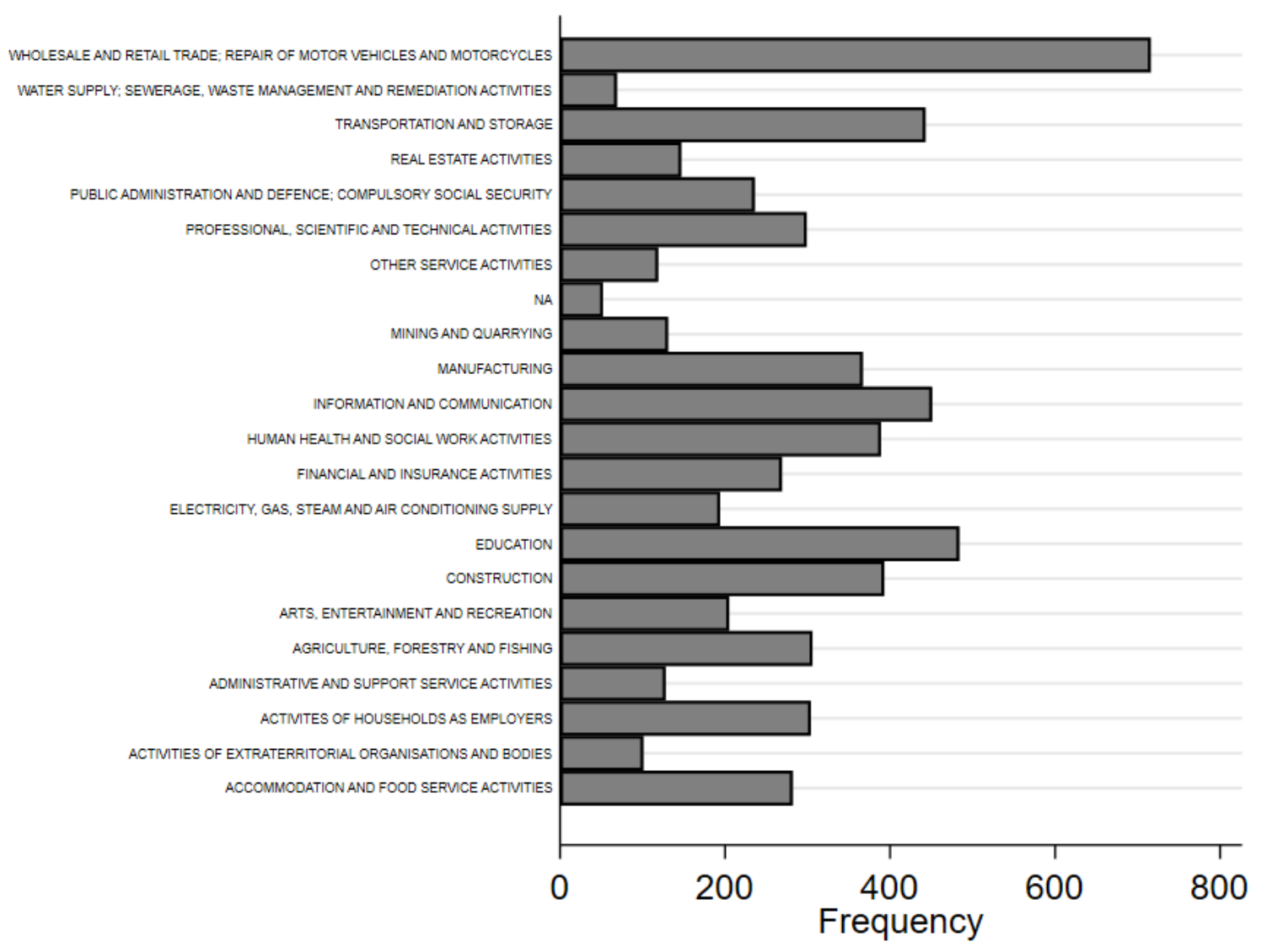

We present some descriptive information on the distribution of firms across sectors and sizes in Figures 3 and 4. We use NACE two-digit sector codes to classify firm sectors. Figures 3 and 4 demonstrate that our data contain information on firms of of varying sizes operating across a wide variety of sectors. To compare how our sampled data compared to the observed distribution of firms, we use sector data from the Ukrainian firm census. While we are unable to use a similar census to examine the representativeness of our Venezuelan or Egyptian sample, the difference between firm proportions in our sample vs. the Ukrainian firm census 
Figure 4: Sample Firm Size Distribution

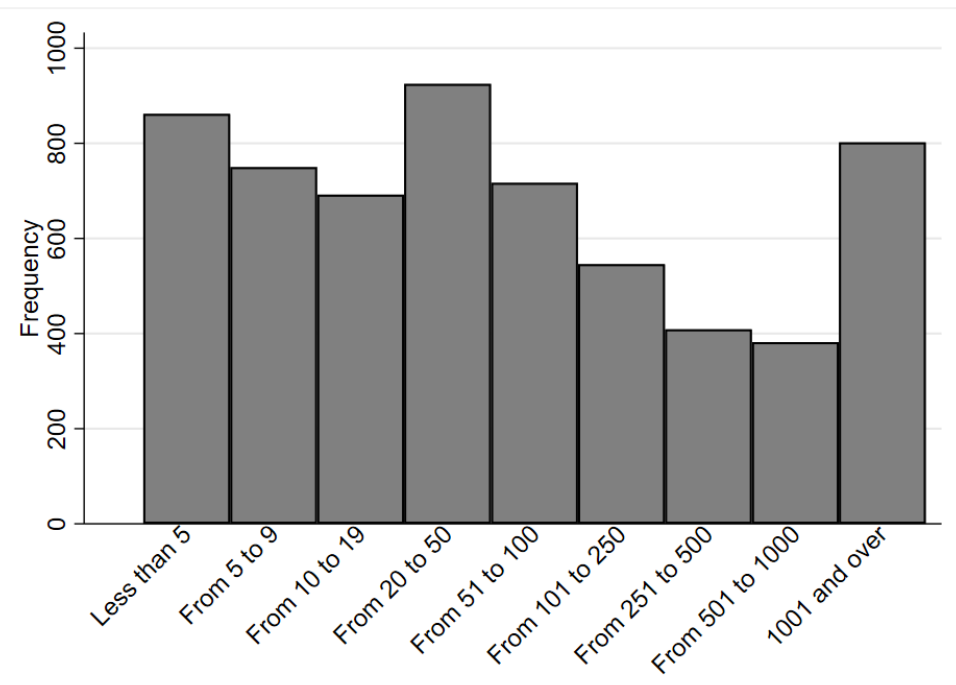

Figure 5: Ukraine Sample and Census Sector Distribution

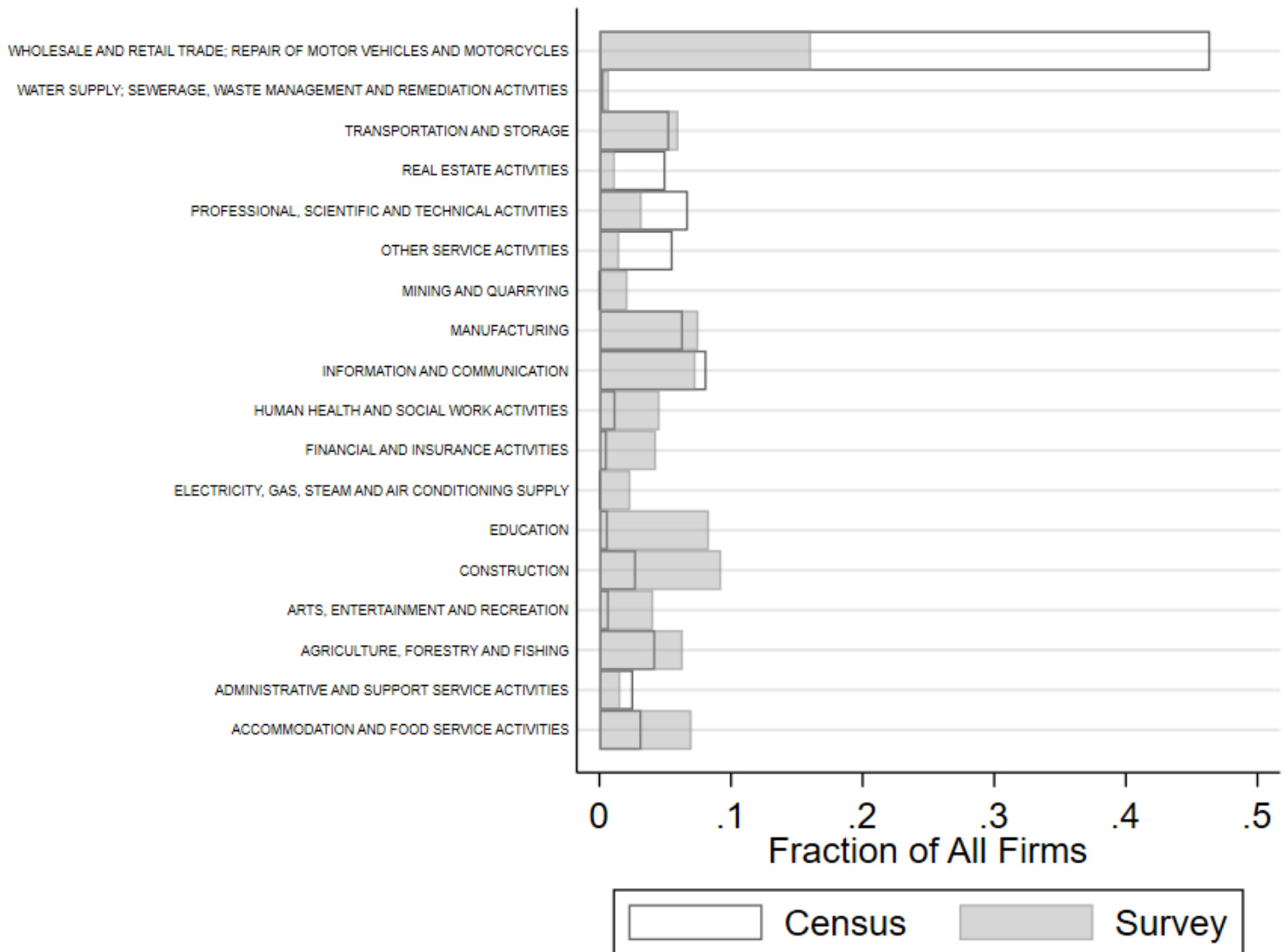


is still informative. We present these differences in Figure 5. While our data over-samples educational firms and under-samples retail firms, our sampled sector distributions generally approximate the proportions reported in the firm census. This increases our confidence that our sample is generally representative of the distribution of firms in the economy.

Respondents to the survey were asked to answer a variety of questions soliciting information on firm characteristics, experiences with governments involving direct occurrences and interactions, as well as various opinions and perceptions.

To measure political connections, we use information from two variables. First, we ask respondents to rate the political connections of their firms on a scale ranging from $0-10$, where 0 indicates no connections and 10 indicates very strong connections. ${ }^{4}$ This formulation is more perceptual: we rely on the respondent's idiosyncratic estimation and interpretation of the firm's political connections and may include difficult-to-quantify informal relationships between the company and power brokers. Second, we ask respondents if their firm has a manager, CEO, owner or board member who are current or former members of parliament, high-ranking or low-ranking bureaucrats. We use a count of the total number of high-ranking officials and parliament members that are associated with a given firm to measure these formal ties. Firms are likely to have strong political ties if multiple high-ranking officials or parliament members have a stake in ensuring the continued success of a firm and have an incentive to use their influence on behalf of the firm.

\subsection{Experimental Treatment}

In this three-country survey we included a conjoint experiment for identification of the causal relationship between a firm's political connections and the level of investment it might receive. To do so, we asked respondents to evaluate a series of hypothetical investment scenarios in which they divide some amount of money between two firms. Respondents are presented with a variety of information on firms' characteristics, including political ties. In

\footnotetext{
${ }^{4}$ The Appendix contains the questions used in these analyses.
} 
theory, if political connections are valuable to the firm-as much of the existing literature holds to be true in general-then we should expect more connected firms to receive more investment. By including numerous other attributes, we can make the scenarios much more compelling while also learning about the effects of a variety of criteria on investment decisions. We preregistered the design with SocArchiv and include the pre-registration in our supplementary information.

Our experiment has the format of a choice-based conjoint design between two alternatives, except that in this case, the respondent is choosing how to allocate a $\$ 100$ investment between two companies. The amount invested is a somewhat arbitrary number and we use $\$ 100$ because it is mathematically simple to divide. We have respondents choose between two options because it reduces satisficing: respondents need to consider different options and choose which one is best rather than opting for the first they see on the screen (Hainmueller, Hangartner and Yamamoto 2015). In addition, the forced-choice design ensures that investment happens. If we only presented a single option, risk-averse respondents may never choose to invest at all.

The possible attributes for this experiment include company ownership, company country of origin, sector, number of employees, current assets $(\$)$, total sales $(\$)$, total profit $(\$)$, age of firm, and political connections. Given all these attributes is important to note that the respondent could well see company profiles which would be unlikely to be observed in their country. However, as our primary inference problem is sample selection bias, we note that randomization requires the respondent to see options which they would not normally otherwise see so that we can learn about these counterfactuals.

We sought to make the experiment as realistic as possible by generating plausible corporate data. For the economic attributes of the firm, we simulate from continuous distributions to approximate realistic investment decisions. We first draw the number of employees from series of uniform distributions that take $20 \%$ of samples from the following bounds: (10 50), (50 - 100), (100 - 500), (500 - 1000) and (1000 - 5000). This produces a distribution with 
substantial mass in medium and small firms, with relatively fewer larger firms (greater than 1,000 employees). We draw the amount of capital as dollars per employee from a uniform distribution with a minimum of $\$ 100$ and a maximum of $\$ 10000$, and we draw a number of years for firm age from a uniform distribution between 3 and 65 .

One of the challenges in designing a realistic investment scenario is to have data that an investor might expect about firm performance. Due to our uncertainty about how best to show data about a company, we take two approaches to manipulating corporate performances. First, we draw from a simple Likert list of attributes for firm profitability that run from Losing a Lot of Money to Very Profitable ( 5 categories). This approach uses heuristics to reduce information load for the respondent when evaluating treatment profiles at the risk of reduced realism for the profiles.

Our second approach was to provide the respondent with much more detailed randomized information about firm performance. To accomplish this, we generated individualized time series for each investment profile, which we then presented as time series graphs to the respondent. To generate the series, we drew time-varying total factor productivity $a_{i t}$ value for each treatment. Conditional on these draws, we then calculated the amount of sales $q_{i t}$ and profit $p_{i t}$ for firm $i$ in year $t$ through a Cobb-Douglas production function given fixed values for labor $L_{i}$, capital $K_{i}$, and time-varying TFP $a_{i t}$ :

$$
\begin{aligned}
& q_{i t}=a_{i t} \sqrt{L_{i}} \sqrt{C_{i}} \\
& p_{i t}=q_{i t}-\sqrt{L_{i}} \sqrt{C_{i}}
\end{aligned}
$$

We used the square root of capital and labor to ensure constant returns to scale. Profit $p_{i t}$ is equal to the amount of sales minus the same production function with unit TFP. In other words, TFP determines the amount of profit a firm receives.

To allow TFP to vary over the lifetime of the firm, we drew two parameters $C_{1}$ and $C_{2}$ 
and generated TFP $a_{i t}^{\prime}$ via a quadratic function on the real line as a function of time $t$ :

$$
\begin{aligned}
& a_{i t}^{\prime}=\alpha+C_{1} a_{i t} t+C_{2} a_{i t} t^{2} \\
& a_{i t}=e^{a_{i t}^{\prime}}
\end{aligned}
$$

We exponentiated $a_{i t}^{\prime}$ to $a_{i t}$ because TFP must be a strictly positive parameter. Using a quadratic function for TFP allows the performance of the firm to vary over time in relatively smooth shapes, either concave-up, concave-down, convex-up or convex-down. It is also possible to have concave-convex and convex-concave shapes over the span of the firm, which would constitute S-curves where company performance decreased for a period and then increased for a period. To illustrate what the resulting TFP values look like, we drew 1000 random variates for a 100-time point trend and plotted them in Figure 6. This figure shows that we can capture a wide variety of shapes in this distribution that are all plausible ways that productivity (and hence profitability) could change in a firm over time. The respondent was not shown the TFP values directly (as they are in principle unobservable), only the net profit above or below sales.

The potential drawback of this approach is that it increased the information load of the treatment, possibly making it more difficult for the respondent to evaluate the treatment profile and leading to satisficing. The advantage of this version of the treatment is that is much more realistic and detailed than the Likert scale. Because of our uncertainty about which version would produce the most valid results, we randomized equally whether the respondent received a Likert scale for profitability or a full time series plot. We report results from this experiment-within-experiment in the supplementary information. In brief, it appeared that the inclusion of the time series plot caused respondents to spend about four additional minutes evaluating the profiles, possibly signaling increased cognitive load but also a higher quality of responses. 
$2.0-$



Figure 6: 1000 Draws of Random Time-Varying TFP Trajectories 
Table 1: Treatment Profiles for Investment Conjoint Survey Experiment

\begin{tabular}{lll} 
Number $\quad$ Attribute & Values \\
\hline 1 & Ownership & $\begin{array}{l}100 \% \text { Foreign-Owned, Domestic Private, Domestic } \\
\text { Public }\end{array}$ \\
& United States, Germany, Saudi Arabia, China, Russia, \\
& Brazil, South Korea, Japan, Saudi Arabia
\end{tabular}

The rest of the attributes have discrete values, which we show in Table 1 . We measure political connections in numerous ways to try to capture the variety of relationships a company could have with the state. For example, either an owner or a board member could be politically-connected, and this relationship could be one of professional acquaintance (i.e. a former minister or bureaucrat) or one of friendship (former classmate) or familial tie (son-inlaw, daughter-in-law, etc). This diversity in treatment type allows us to marginalize over all these possible kinds of connections so that when we present aggregated results we can know with confidence that the results are not simply due to the particular political connection of a certain type. In addition, we can know with much more precision what kind of political connections tend to be most or least valuable.

In the experiment, respondents view two randomly generated company profiles paired together and are asked to choose some investment amount $x \in[0,100]$ to invest in one firm versus the other. Respondents evaluate four sets of investment pairs (i.e., tasks) and 
consequently assign investment amounts to 8 hypothetical firms. We present one example of a pair of randomly generated profiles in Figure 7. This version of the figure shows the time-varying profitability and sales of the firm as parallel plots. We believe that this visual depiction communicates more realism about the hypothetical companies, though possibly also produces an additional informational burden on the respondent. As we discussed, for this reason we randomly substituted a Likert scale in $50 \%$ of the profiles.

\section{Results}

We present the experimental results both in terms of dis-aggregated treatments (i.e., all the different types of political connections) along with aggregated results in which the treatment indicator is binary (connected or unconnected). We use the binary indicator to see if treatment interactions tend to vary as predicted by our theory. To model the outcome, which is a bounded variable between 0 and 1, we use a modified form of beta regression (Kubinec 2020) with Bayesian Markov Chain Monte Carlo estimation with Stan (Carpenter, Gelman, Hoffman, Lee, Goodrich, Betancourt, Brubaker, Guo, Li and Riddell 2017). The results are presented as logit coefficients and have a similar interpretation to standard logistic regression..$^{5}$

Figure 8 shows all of the possible versions of political connections disaggregated in the standard form for presenting conjoint results, while Figure 9 shows the rest of the conjoint survey attributes along with a collapsed binary indicator for whether a company had any type of political connections. As can be seen, while there are a wide varieties of ways that we coded political connections, the results show that the effect of connections is always negative. While some effects are larger than others-generally speaking, having an owner who is politically connected appears to be worse than having a board member who is politically connected-on the whole, there is considerable uniformity in how respondents evaluated po-

\footnotetext{
${ }^{5}$ OLS results are similar for most models though we present these results as the distribution of the error term is more realistic for a DV with upper and lower bounds.
} 
Figure 7: Conjoint Experiment

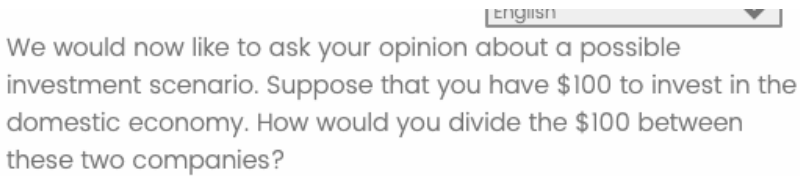

The following table contains data about these two investment options:

\begin{tabular}{|c|c|c|}
\hline Company A & & $\begin{array}{l}\text { Company B } \\
\text { at o }\end{array}$ \\
\hline Domestic - Public & Ownership & $\begin{array}{l}\text { Domestic - } \\
\text { Private }\end{array}$ \\
\hline Egypt & Country & Egypt \\
\hline Telecommunications & Sector & Manufacturing \\
\hline 24 & Employees & 473 \\
\hline$\$ 166.89 k$ & $\begin{array}{c}\text { Current } \\
\text { Assets (\$) }\end{array}$ & $\$ 1.56 \mathrm{M}$ \\
\hline 40 years & Age of Firm & 49 years \\
\hline $\begin{array}{l}\text { Owner is married to } \\
\text { the President's son }\end{array}$ & $\begin{array}{c}\text { Government } \\
\text { Relations }\end{array}$ & $\begin{array}{l}\text { Member of } \\
\text { parliament is on } \\
\text { board of } \\
\text { company }\end{array}$ \\
\hline Sales Onar Time & $\begin{array}{c}\text { Company } \\
\text { Performance } \\
\text { (\$) }\end{array}$ & Siles Curr Tma \\
\hline$\$ 50$ & $\begin{array}{l}\text { Amount } \\
\text { Invested }\end{array}$ & $\$ 50$ \\
\hline
\end{tabular}

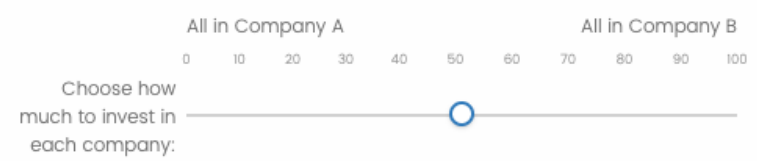

litical connections: they did not like them. This result went against both our intuitions and what we believe to be the dominant message in the literature that political connections help companies secure higher returns and thus should be more attractive vehicles for investment.

However, while we are surprised at the direction of the finding, we are not surprised at 


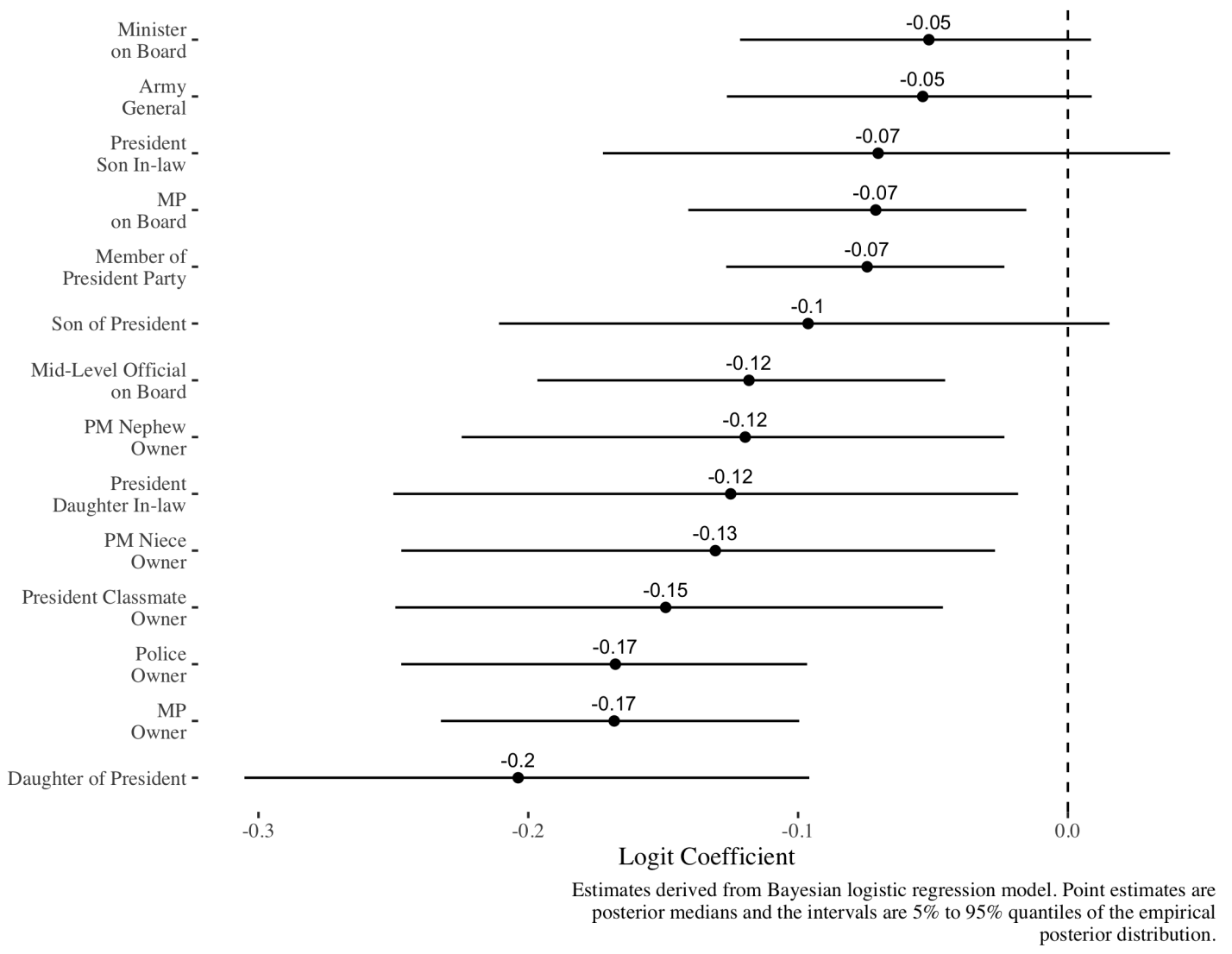

Figure 8: Dis-aggregated Political Connection Treatments

being surprised. As we expressed in the previous section, there are serious inference problems to overcome in estimating the effect of political connections that is free of the influence of long-term selection biases, and for that reason it is not surprising that our estimates depart from the observational data in the literature. We interpret this result as implying there is still much we do not know how political connections affects economic decision-making, and we do our best in the rest of this paper to provide what we believe are the best explanations for this finding.

In Figure 9 we show the rest of the company attributes and their effects on investment. The plot shows that the factors that seemed to influence respondents most strongly were profitability and country of origin. Unsurprisingly, respondents invested the most in companies that were the most profitable. To produce a single profitability measure, we combined the continuous and Likert measures for profitability by collapsing the time series into cate- 


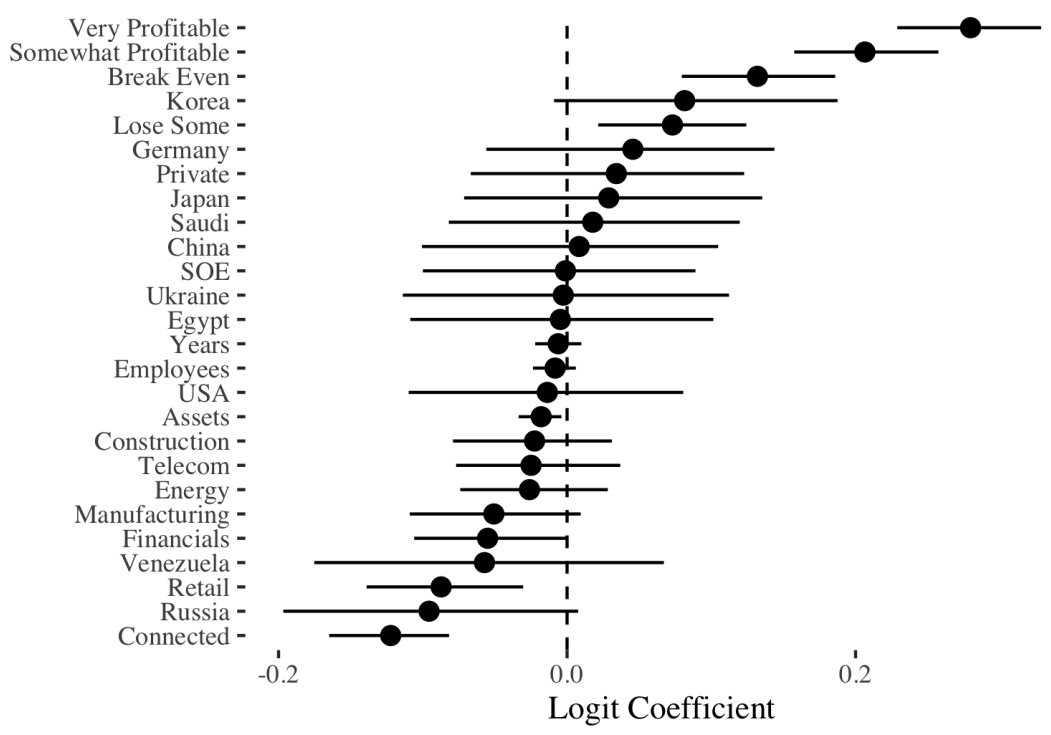

Political connection treatments are collapsed to a single connected vs. unconnected binary treatment. Estimates derived from Bayesian logistic regression model. Point estimates are posterior medians and the intervals are $5 \%$ to $95 \%$

Figure 9: All Attributes in Conjoint Experiment

gories based on concavity, i.e., convex-up profit series were considered the most profitable, and concave-down time series were considered to the least profitable.

Interestingly, companies originally from South Korea and Germany were selected as being more attractive for investment. By comparison, Russia and Venezuela were disfavored. As Venezuela was only shown to Venezuelean respondents, we can interpret the relationship as indicating a preference against domestic firms for Venezuelans, which follows from the level of instability in the country. We note as well that several of the factors did not seem to have much of an effect on investments, at least for the sample as a whole. The age of the firm, the type of firm (i.e. state-owned versus private), and the sector of the firm were not strong predictors of investment decisions. The exception are firms in the retail sector, which were relatively disfavored. Also, we note that respondents did not prefer companies with larger amounts of assets, though as we lack a clear theory to explain this result, we do not further comment on it.

One aspect that is notable in Figures 8 and 9 are that the uncertainty intervals for some coefficients are very large in magnitude. This suggests that there is considerable heterogene- 
ity in how respondents are evaluating companies. We look at treatment effect heterogeneity by the respondent's country, by treatment profile profitability, and by the sector and political connectedness of the respondent's company. First, Figure 10 shows predicted investment shares by respondent sector and indicates that the penalty against politically-connected investments is highest for respondents in water utilities (though very imprecise), the arts, real estate, and scientific/professional and commercial establishments. By comparison, respondents working in construction, health care, restaurants, transportation and public administration (i.e., SOEs) did not discount political connections as much, though the treatment does not become strongly positive. Figure 11 shows predicted values for investment decisions for treatment (connected) and control (unconnected) profiles by country (connections are coded as a binary variable). As can be seen, the treatment group receives less investment than the control group across all three countries, suggesting uniformity in how the treatment operates, though we note that the effect is noticeably larger in Venezuela than other countries. As these are predictions with other variables held at their means, overlapping uncertainty intervals does not necessarily mean the underlying effects are statistically insignificant.

Next we examine how firm performance affects respondents' willingness to invest. In Figure 12 we show how the final time period of our time-varying TFP and time-varying profitability measures affected the willingness of respondents to invest by modeling both continuous variables with a spline to permit non-linear effects. Respondents of course did not observe TFP, only the time series plot of sales and profits. Because TFP represents a measure of how effective or efficient a firm is, it should increase investment. We do observe a very clear association between rising TFP and rising willingness to invest. The average treatment effect for TFP is plotted in panel A of Figure 12 separately for connected (treatment) and unconnected (control) companies, and profitability is likewise shown in panel B. Interestingly, the control group tracks more closely with the overall effect of TFP in that it is uniformly positive. However, for connected firms, TFP does not have as clear an effect. Those with the 


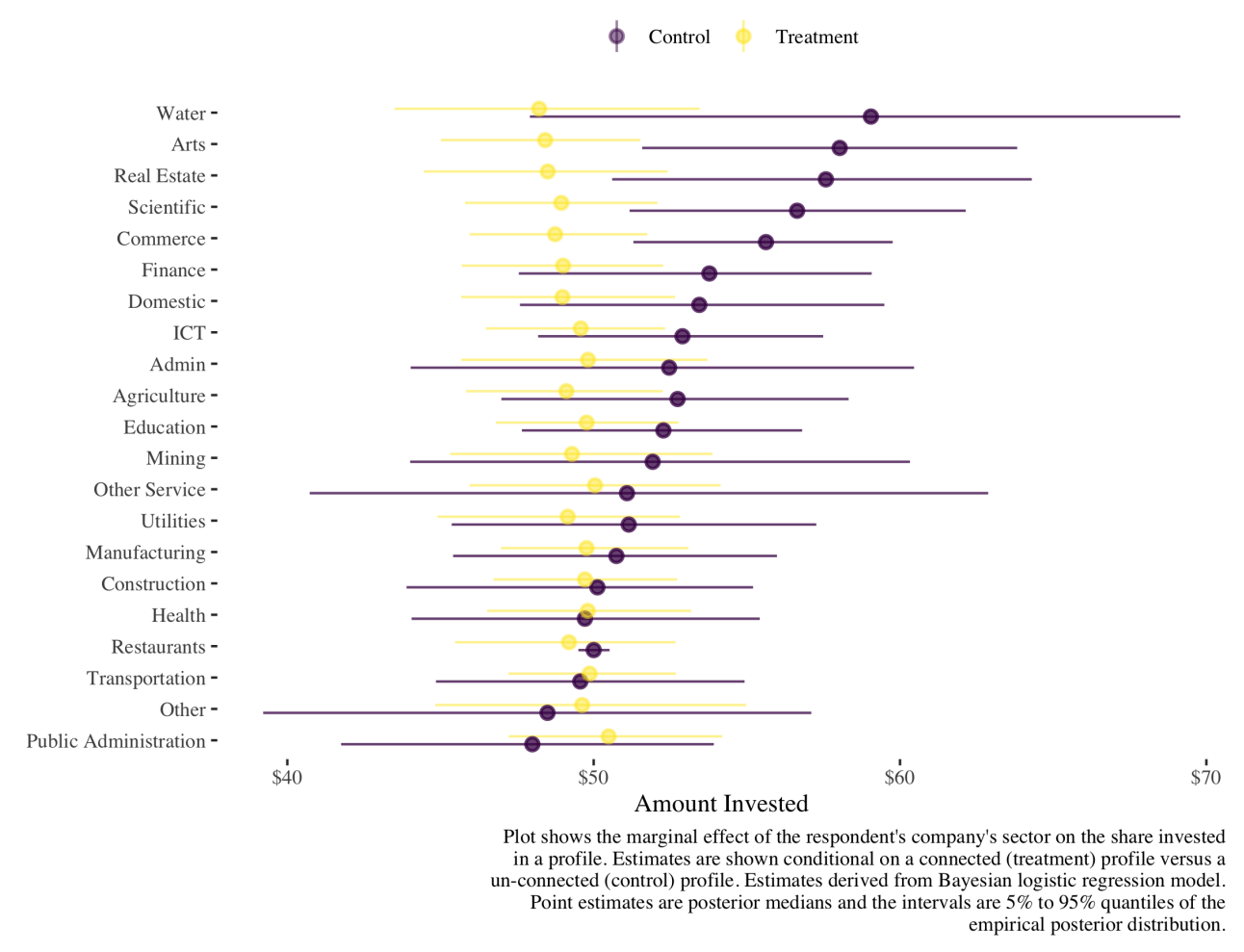

Figure 10: Interaction of Connections and Respondent Company Sector

highest and lowest TFP have approximately equal investment shares. Similarly, connected companies are actually more likely to receive investment when they are very unprofitable versus somewhat profitable. It would appear based on this finding that respondents tended to discount both very bad and very good performance for politically-connected firms. We note that it is an intriguing finding given the fact that politically-connected firms can obtain benefits that have little if anything to do with efficiency, and so it would make sense that TFP would not have a monotonic effect on politically-connected companies.

Finally, we also examine whether a respondent's companies' political connections moderates the relationship between political connections as a treatment and investment decisions. To do so, we interact our two measures of respondent political connections, the 1-10 scores for total connections and the efficacy of connections, with a binary variable for connected vs. non-connected treatment profiles. The results are shown in Figure 13. Panel A in the figure shows the political connections score and panel B the efficacy of those connections, but as 

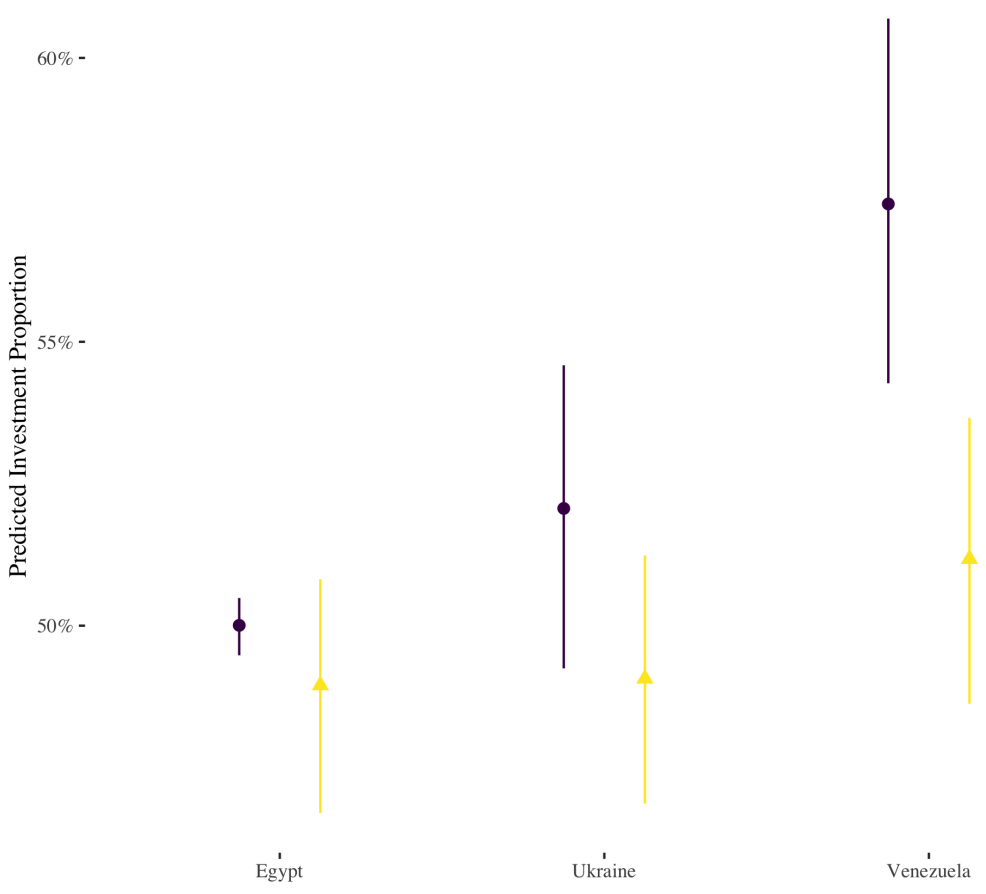

Plot shows political connection treatment interacted with country intercepts.
Estimates derived from Bayesian logistic regression model. Point estimates are Estimates derived from Bayesian logistic regression model. Point estimates are posterior medians and the intervals are 5\% to $95 \%$ quantiles of the empirical

Figure 11: Interaction of Connections and Respondent Country

A

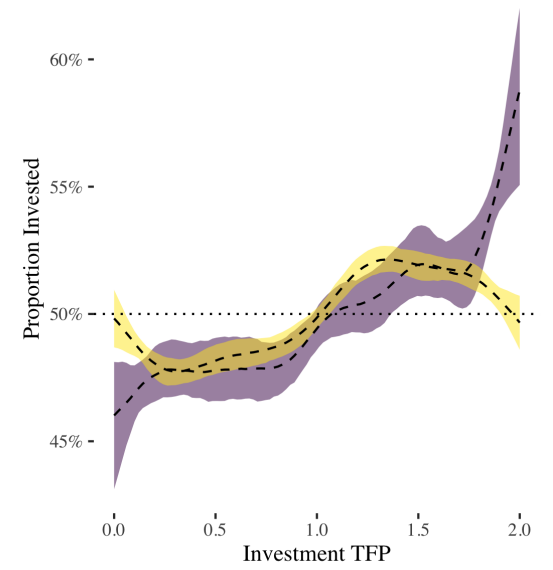

B

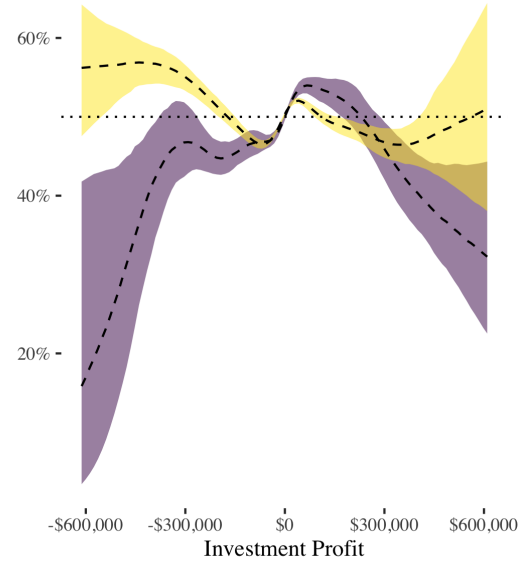

Control Treatment

Plot shows the marginal effect of investment profile TFP (A) and investment profile profit (B) on a respondent choosing a profile. Estimates are shown conditional on a connected (treatment) profile versus a un-connected (control) profile. Estimates derived from (lian logistic regression model with a spline. Point estimates are posterior medians

Figure 12: Total Factor Productivity and Profit as Treatment Moderators 


\section{A}

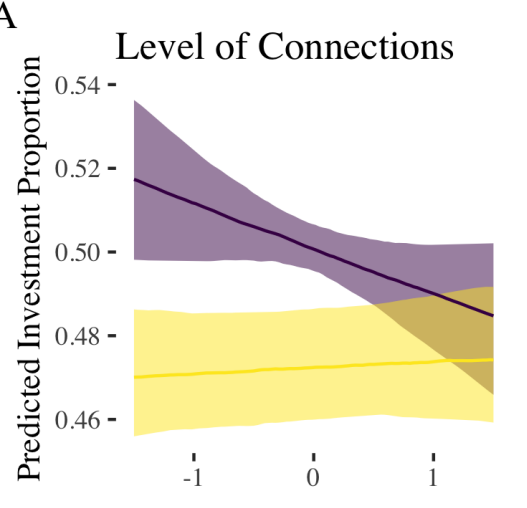

B

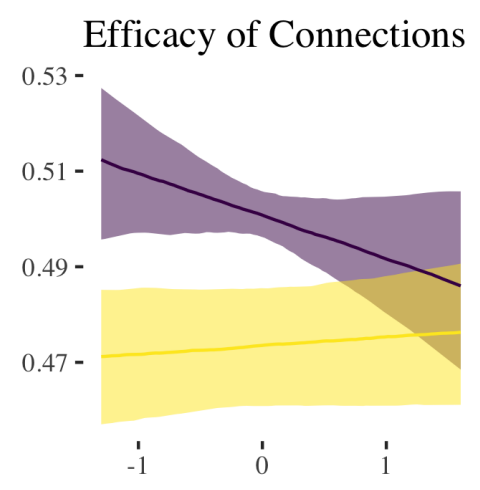

Control

Treatment

Plot shows political connection treatment interacted with the respondent's political connections (A) and the efficacy of those connections (B). Estimates derived from Bayesian logistic regression model. Point estimates are posterior medians and the intervals are $5 \%$ to $95 \%$ quantiles of the empirical posterior distribution.

Figure 13: Interaction of Connections and Respondent Political Connection Variables

can be seen, the results are nearly identical. In either case, as a respondents' companies' connections increase, the probability of selecting a company for investment converges to the control distribution. In other words, respondents at companies that have high political connections that are helping their company do not penalize treatment profiles with connections.

The clear nature of this relationship suggests that a respondents' companies' political connections is indeed a strong moderator of how and whether they penalize a company for being politically-connected. Indeed, this interaction also helps us explain why the aggregate effect of connections is negative for the sample as a whole: because most respondents work at non-connected companies, they are subsequently less likely to select companies for investment that are connected. If our sample was composed entirely of respondents at politicallyconnected companies, we would likely to observe either a null or positive relationship between connections and investment.

While this subgroup relationship sheds light on the negative finding for the relationship between connections and investment, it is still not entirely clear why a respondent's com- 


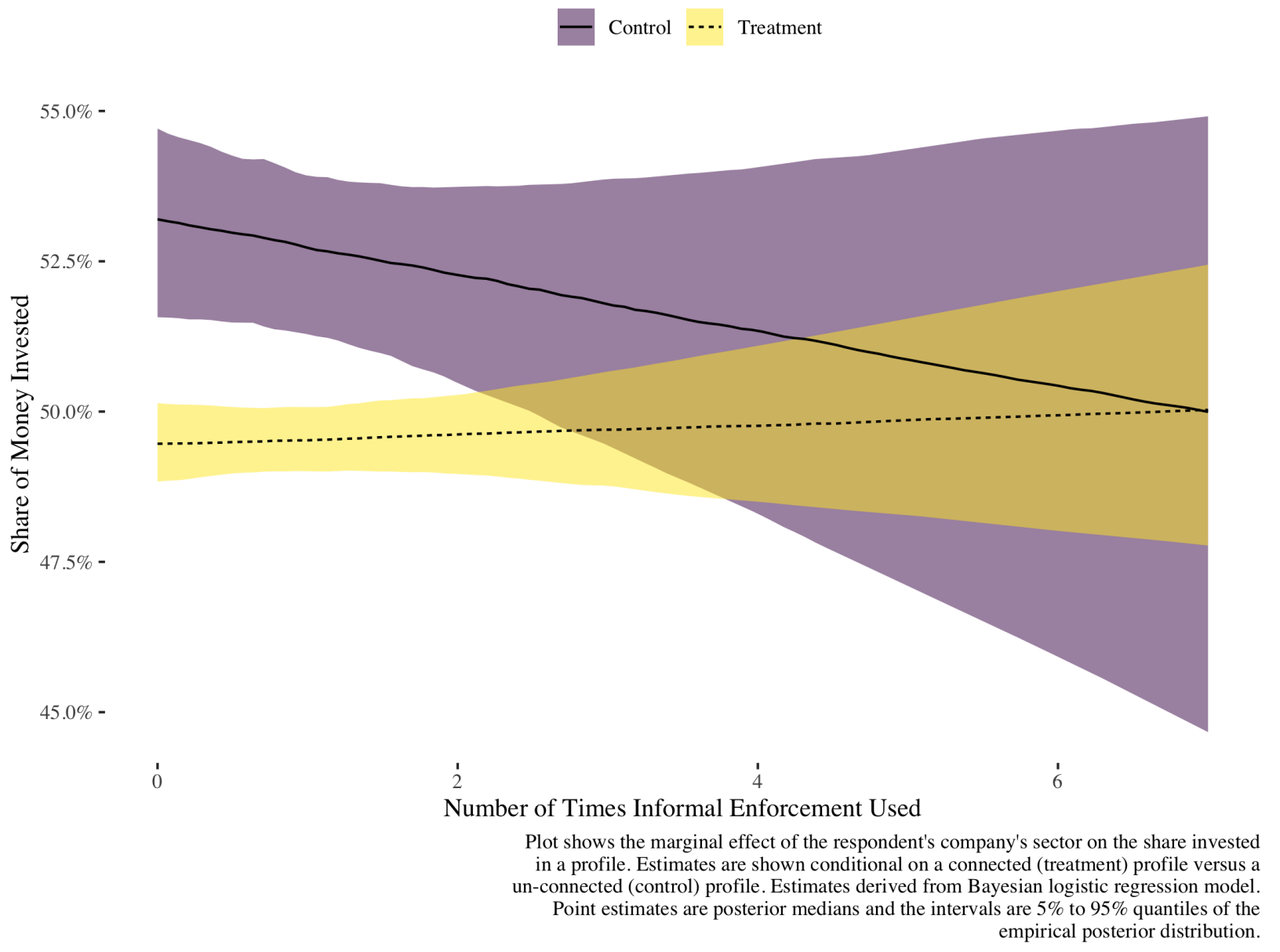

Figure 14: Interaction of Political Connections and Informal Means of Enforcement

pany's connections should matter so much. We believe that this association is explained by similarities in how politically-connected companies operate which encourage cooperation. In particular, we know based on other questions in the survey that politically-connected companies are more likely to use informal rather than formal means of dispute resolution. These back-door, unofficial dispute resolution mechanisms could well dissuade potential investors who fear losing their investment to unaccountable company managers. To test this, we interact the binary treatment with the same count variable for informal means of dispute resolution that we used earlier (i.e., we count all the times that a company reported it used informal means to resolve some problem). We interact this variable and report the results in Figure 14. While the relationship in Figure 14 is less precise than the political connections 
interaction, we can identify a very similar pattern: respondents at companies that are more likely to use informal means of dispute resolution are less likely to penalize companies with political connections as potential investment vehicles. The limitation in terms of uncertainty at the top end of the scale is largely an artifact of the sample because only a minority of our respondents are at politically-connected companies that use informal means of dispute resolution. As a result, the relationship is much more precise for the larger number of companies that do not use informal means of dispute resolution.

\section{Conclusion}

In this paper, in order to better understand how people make investment decisions in countries with poor quality of institutions, we implement an online survey using Facebook advertising to recruit subjects who are either business employees or managers. We use finely

grained information about political connections and experimental manipulations to be able to assess the role of political connections as opposed to other factors. In contrast to what we might expect given the value of political relationships, we find that political connections can be a barrier rather than an aid to inter-firm investment.

On the whole, political connections discourage investment in companies in our experiment, but we find that such an effect is partly explained by the role of political connections at the respondent's company. Respondents in more connected companies and companies that benefited from connections were more likely to choose connected companies, and vice versa. This result strongly suggests that the benefits of political connections to a company are not unequivocal but depend on that company's position vis-a-vis those who are currently in power.

For these reasons, we believe that political connections are a more risky strategy for companies than has often been acknowledged in the literature. At first glance, it seems counter-intuitive that stronger political connections can lead to more government predation 
or expropriation, and that investors do not seem to prefer politically-connected companies.

However, these findings are driven by the highly conditional effects of connections. 


\section{References}

Albertus, Michael and Victor Menaldo. 2012. "If you're against them you're with us: The effect of expropriation on autocratic survival." Comparative Political Studies 45(8):973-1003.

Betz, Timm and Amy Pond. 2019. "Foreign Financing and the International Sources of Property Rights." World Politics 71(3):503-541.

Bhandari, Abhit. 2020. "Political Determinants of Economic Exchange: Evidence from a Business Experiment in Senegal." American Journal of Political Science.

Campos, J Edgardo, Donald Lien and Sanjay Pradhan. 1999. "The impact of corruption on investment: Predictability matters." World development 27(6):1059-1067.

Carpenter, Bob, Andrew Gelman, Matthew D. Hoffman, Daniel Lee, Ben Goodrich, Michael Betancourt, Marcus Brubaker, Jiqiang Guo, Peter Li and Allen Riddell. 2017. "Stan: A Probabilistic Programming Language." 76(1).

Claessens, Stijn, Erik Feijen and Luc Laeven. 2008. "Political connections and preferential access to finance: The role of campaign contributions." Journal of financial economics 88(3):554-580.

Faccio, Mara, Ronald W Masulis and John J McConnell. 2006. "Political connections and corporate bailouts." The Journal of Finance 61(6):2597-2635.

Farrell, Henry. 2005. "Trust and Political Economy: Institutions and the Sources of Interfirm Cooperation." Comparative Political Studies 38(5):459-483.

Fedenia, Mark, James E. Hodder and Alexander J. Triantis. 1994. "Cross-Holdings: Estimation Issues, Biases, and Distortions." The Review of Financial Studies 7(1):61-96.

Fisman, Raymond. 2001. "Estimating the value of political connections." American economic review 91(4):1095-1102.

Fried, Brian J, Paul Lagunes and Atheendar Venkataramani. 2010. "Corruption and inequality at the crossroad: A multimethod study of bribery and discrimination in Latin America." Latin American Research Review pp. 76-97.

Frye, Timothy and Andrei Yakovlev. 2016. "Elections and property rights: a natural experiment from Russia." Comparative Political Studies 49(4):499-528.

Galang, Roberto Martin N. 2012. "Victim or victimizer: Firm responses to government corruption." Journal of Management Studies 49(2):429-462.

Gans-Morse, Jordan. 2017. "Demand for Law and the Security of Property Rights: The Case of Post-Soviet Russia." American Political Science Review 111(2):338-359.

Hainmueller, Jens, Dominik Hangartner and Teppei Yamamoto. 2015. "Validating vignette and conjoint survey experiments against real-world behavior." Proceedings of the National Academy of Sciences of the United States of America 112(8):2395-2400. tex.owner: saudiwin tex.timestamp: 2016.12.27.

Henisz, W. J. 2000. "The institutional environment for multinational investment." The Journal of Law, Economics, and Organization 16(2):334-364.

Jensen, Nathan. 2008. "Political risk, democratic institutions, and foreign direct investment." The Journal of Politics 70(4):1040-1052.

Jensen, Nathan M. 2003. "Democratic governance and multinational corporations: Political regimes and inflows of foreign direct investment." International organization 57(3):587-616. 
Keillor, Bruce D, Timothy J Wilkinson and Deborah Owens. 2005. "Threats to international operations: dealing with political risk at the firm level." Journal of Business Research 58(5):629-635.

Kobrin, Stephen J. 1987. "Testing the bargaining hypothesis in the manufacturing sector in developing countries." International organization 41(4):609-638.

Kubinec, Robert. 2020. "Ordered Beta Regression: A Parsimonious, Well-Fitting Model for Survey Sliders and Visual Analog Scales." SocArchiv .

Li, Quan. 2009. "Democracy, autocracy, and expropriation of foreign direct investment." Comparative Political Studies 42(8):1098-1127.

Li, Quan and Adam Resnick. 2003. "Reversal of fortunes: Democratic institutions and foreign direct investment inflows to developing countries." International organization 57(1):175-211.

Markus, Stanislav. 2012. "Secure Property as a Bottom-Up Process: Firms, Stakeholders, and Predators in Weak States." World Politics 64(2):242-277.

Markus, Stanislav. 2015. Property, Predation, and Protection. Cambridge University Press.

Marques, Israel, Irina Levina, Anton Kazun and Andrei Yakovlev. 2020. "Calling the cavalry: firm-level investment in the face of decentralized expropriation." Journal of Institutional Economics 16(4):503-518.

Mauro, Paolo. 1997. Economic Issues No. 6 - Why Worry About Corruption? Technical report International Monetary Fund.

Nielsen, Bo Bernhard. 2007. "Determining international strategic alliance performance: A multidimensional approach." International Business Review 16(3):337-361.

Qian, Meijun, Hongbo Pan and Bernard Yin Yeung. 2010. Expropriation of Minority Shareholders in Politically Connected Firms. Number ID 1719335.

URL: https://papers.ssrn.com/abstract=1719335

Roberts, Brian E. 1990. "A dead senator tells no lies: Seniority and the distribution of federal benefits." american Journal of Political science pp. 31-58.

Samphantharak, Krislert and Edmund J Malesky. 2008. "Predictable corruption and firm investment: evidence from a natural experiment and survey of Cambodian entrepreneurs." Quarterly Journal of Political Science 3:227-267.

Schoenherr, David. 2018. "Political connections and allocative distortions." Journal of Finance, forthcoming

Shleifer, Andrei and Robert W Vishny. 1993. "Corruption." The quarterly journal of economics 108(3):599617.

Tanzi, Vito and Hamid Davoodi. 1998. Corruption, Public Investment, and Growth. In The Welfare State, Public Investment, and Growth, ed. Hirofumi Shibata and Toshihiro Ihori. Tokyo: Springer Japan pp. 4160.

Wei, Shang-Jin. 1997. Why is corruption so much more taxing than tax? Arbitrariness kills. Technical report National bureau of economic research.

Williamson, Oliver E. 1979. "Transaction-Cost Economics: The Governance of Contractual Relations." Journal of Law and Economics 22(2):233-261. 